\title{
Proteomic analysis of endothelial progenitor cells exposed to oxidative stress
}

\author{
YING LIU ${ }^{1 *}$, JUN WEI $^{2,3^{*}}$, MING CHANG ${ }^{4}$, ZHIQIANG LIU ${ }^{4}$, DAWEI LI ${ }^{4}$, SHENGYING HU $^{5}$ and LINSEN HU \\ ${ }^{1}$ Department of Neurology, the Second Affiliated Hospital of Dalian Medical University, Dalian, Liaoning 116023; \\ ${ }^{2}$ Institute of Neurology, China Three Gorges University; ${ }^{3}$ Department of Neurology, Yichang Central People's Hospital, \\ Yichang, Hubei 443000; ${ }^{4}$ Department of Neurology, The First Hospital, Jilin University, Changchun, Jilin 130021; \\ ${ }^{5}$ Cardiovascular Department, The First Hospital, Jilin University, Changchun, Jilin 130021, P.R. China
}

Received February 21, 2013; Accepted May 30, 2013

DOI: $10.3892 /$ ijmm.2013.1419

\begin{abstract}
Endothelial progenitor cells (EPCs) repair vascular damage and participate in neovascularization. Accumulating evidence has demonstrated that EPCs have therapeutic potential in reactive oxygen species (ROS)-mediated vascular diseases. In this study, to investigate the effects of oxidative stress on EPCs, EPCs were treated with $\mathrm{H}_{2} \mathrm{O}_{2}$ at different final concentrations for $3 \mathrm{~h}$. MTT assay, scratch-wound assay and Matrigel invasion assay revealed that cell proliferation, migration and tubule formation and function, respectively, were impaired under $\mathrm{H}_{2} \mathrm{O}_{2}$ stress in a concentration-dependent manner. To determine protein response to $\mathrm{H}_{2} \mathrm{O}_{2}$ stress, two-dimensional differential in-gel electrophoresis (2D-DIGE) combined with matrix-assisted laser desorption-ionization time-of-flight (MALDI-TOF/TOF) mass spectrometry were performed. The results revealed that triosephosphate isomerase and ADP-sugar pyrophosphatase were downregulated, while peroxiredoxin-2, thioredoxin-dependent peroxide reductase, mitochondrial (Prx-3), peroxiredoxin-6, EGF-containing fibulin-like extracellular matrix protein 1,
\end{abstract}

Correspondence to: Professor Linsen Hu, Department of Neurology, The First Hospital, Jilin University, 71 Xinmin Street, Changchun, Jilin 130021, P.R. China

E-mail: hulinsen@hotmail.com

${ }^{*}$ Contributed equally

Abbreviations: ASK1, apoptosis signal-regulating kinase 1; EFEMP1, EGF-containing fibulin-like extracellular matrix protein 1; EPCs, endothelial progenitor cells; GPx-1, glutathione peroxidase-1; IEF, isoelectric focusing; IFs, intermediate filaments; MnSOD, manganese superoxide dismutase; NUDT5, ADP-sugar pyrophosphatase; PBS, phosphate-buffered saline; Prx, peroxiredoxin; Prx-2, peroxiredoxin-2; Prx-3, peroxiredoxin-3/thioredoxin-dependent peroxide reductase, mitochondrial; Prx-6, peroxiredoxin-6; Rab GDI $\alpha$, Rab GDP dissociation inhibitor $\alpha$; ROS, reactive oxygen species; TIM, triosephosphate isomerase

Key words: endothelial progenitor cell, oxidative stress, proteomics, antioxidative enzyme, cytoskeleton protein, protective protein vimentin and Rab GDP dissociation inhibitor $\alpha$ were upregulated in the $\mathrm{H}_{2} \mathrm{O}_{2}$-treated EPCs. To further confirm the results from mass spectrometry, the expression pattern of Prx-3 in response to $\mathrm{H}_{2} \mathrm{O}_{2}$ stress was examined by western blot analysis. The data presented in this study provide novel insight into the defensive mechanisms of EPCs and the pathways of oxidative damage in an oxidative environment.

\section{Introduction}

Accumulating evidence suggests that endothelial progenitor cells (EPCs) are recruited to the sites of injury, participate in the repair of damaged tissue, form new vessels in ischemic areas and attenuate the development and progression of atherosclerosis (1-4). Several preclinical studies using animal models have shown the therapeutic efficacy of EPCs in ischemic disorders and vascular injury (1,4-6). Additionally, small-scale clinical trials, including directly injecting EPCs into infarcted tissue or injecting pro-angiogenic cytokines into target tissue to increase EPC number and function, have been performed successfully in patients with cardiovascular diseases (7-9).

Previous studies have demonstrated that multiple pathological conditions can increase the production of reactive oxygen species (ROS) in the vascular wall, including hypercholesterolemia, diabetes and hypertension (10). Increased oxidative stress impairs endothelial function and mediates atherosclerosis, stroke, cardiovascular diseases and numerous other vascular diseases (11-13). Moreover, studies have demonstrated that EPCs exhibit high resistance to oxidative stress, which is a characteristic feature of stem cells (14-16). It has also been demonstrated that the higher expression of intracellular antioxidative enzymes, such as catalase, manganese superoxide dismutase (MnSOD) and glutathione peroxidase-1 (GPx-1) in EPCs, as opposed to mature endothelial cells, is a critical mechanism through which EPCs are protected against oxidative stress (14-16). However, other studies have suggested that the increased expression of apoptosis signal-regulating kinase 1 (ASK1) diminishes the vessel-forming ability of EPCs following exposure to oxidave stress (13). Nevertheless, despite the proteins identified in EPCs upon exposure to oxidative stress, the global protein profile in EPCs remains elusive. In this study, to determine protein response to oxidative stress 
in EPCs, we systematically surveyed the changes in protein expression patterns in EPCs treated with $\mathrm{H}_{2} \mathrm{O}_{2}$ by two-dimensional (2D) gel/matrix-assisted laser desorption-ionization time-of-flight (MALDI-TOF/TOF) mass spectrometry (MS).

\section{Materials and methods}

Cell culture. EPCs (Lonza, Walkersville, MD, USA) were maintained in pre-warmed ECFC growth medium (EBM-2 basal medium supplemented with EGM-2 SingleQuot cryovials and ECFC serum supplement; Lonza) and then seeded in T-75 culture flasks pre-coated with rat tail collagen I (BD Biosciences, Bedford, MA, USA) in a $37^{\circ} \mathrm{C}$ humidified atmosphere with $5 \% \mathrm{CO}_{2}$. The culture medium was replaced with fresh, warm medium every 2 days until the cells reached $70-80 \%$ confluency. EPC monolayers were passaged.

MTT assay. The effect of $\mathrm{H}_{2} \mathrm{O}_{2}$ on EPC proliferation was determined by MTT assay. Early- passage EPCs (passages 4-8) were seeded in a 96-well tissue culture plate pre-coated with type I rat tail collagen $(6,000-7,000$ cells/well). The following day, the cells were either left untreated or treated with increasing concentrations of $\mathrm{H}_{2} \mathrm{O}_{2}$ in quintuplicate for $3 \mathrm{~h}$. The medium was then replaced with fresh, warm medium supplemented with $10 \mu \mathrm{l}$ of MTT $(5 \mathrm{mg} / \mathrm{ml})$. Four hours after incubation, the supernatant was discarded and the EPCs were shaken with $200 \mu \mathrm{l}$ of DMSO for $10 \mathrm{~min}$. The OD value was measured at $490 \mathrm{~nm}$.

Scratch-wound assay. To determine the migration activity of EPCs, the cells were seeded in 24-well tissue culture plates. After reaching 80-90\% confluency, the cells were pre-treated with $\mathrm{H}_{2} \mathrm{O}_{2}$ for $3 \mathrm{~h}$, then the monolayer EPCs were scrapewounded with a sterile micropipette tip to create a denuded zone (gap) of constant width. After washing with phosphate-buffered saline (PBS) to remove the cell debris, the cells were incubated in fresh, warm medium for a further $18 \mathrm{~h}$. The monolayer scratched cells were observed under an inverted phase-contrast microscope with a x10 objective (Olympus, Tokyo, Japan), and images were acquired using a color camera (Olympus) immediately after wounding and $18 \mathrm{~h}$ after wounding. The percentage of wound closure was estimated using the following equation: wound closure $(\%)=\left[1-\left(\right.\right.$ wound area at $\mathrm{T}_{\mathrm{t}} /$ wound area at $\left.\left.\mathrm{T}_{0}\right)\right]$ $\mathrm{x} 100 \%$, where $\mathrm{T}_{\mathrm{t}}$ is the time after wounding and $\mathrm{T}_{0}$ is the time point of wounding. Five fields/well were examined and 5 independent experiments were performed.

Matrigel invasion assay. The EPCs that were either untreated or pre-treated with an increasing concentrations of $\mathrm{H}_{2} \mathrm{O}_{2}$ for $3 \mathrm{~h}$, were seeded at 15,000 cells/well in 96-well tissue culture plates coated with $50 \mu \mathrm{l}$ of Matrigel (BD Biosciences). Following incubation at $37^{\circ} \mathrm{C}$ for 8 or $24 \mathrm{~h}$, the cells in the central field of each well were observed under an inverted phase-contrast microscope with a x10 objective (Olympus), and images were acquired photographed using a color camera (Olympus). The total vessel length of each image was calculated from the captured images using Image-Pro Plus software. Closed network units of the central visual field of each well were enumerated by visual inspection. Three independent experiments were performed.
Proteomic sample preparation. The cells (passages 4-7) were harvested and washed 3 times with ice-cold PBS. The cells were then lysed with lysis buffer (7 M urea, $2 \mathrm{M}$ thiourea, $4 \%$ CHAPS, $30 \mathrm{mM}$ Tris, $\mathrm{pH} 8.8$ ) containing 1\% protease inhibitors and nuclease mix. Following centrifugation at $25,000 \mathrm{x} \mathrm{g}$ for $30 \mathrm{~min}$, the supernatants were collected. Proteins in the supernatant were cleaned up and quantified using a Clean-up kit and 2-D Quant kit (GE Healthcare, Uppsala, Sweden) according to the manufacturer's instructions.

Two-dimensionaldifferentialin-gel electrophoresis(2D-DIGE). Following the manufacturer's instructions, $50 \mu \mathrm{g}$ of proteins from each sample were minimally labelled with fluorescent dyes. Following incubation on ice for $30 \mathrm{~min}$, the reaction was terminated by the addition $1 \mu \mathrm{l}$ of $10 \mathrm{mM}$ lysine. Cy3-, Cy5and Cy2-labelled samples and internal standards were pooled and then rehydration buffer [8 $\mathrm{M}$ urea, 2\% CHAPS, 0.4\% IPG buffer and $0.28 \%$ dithiothreitol (DTT)] was added to gain equal volumes. The samples were loaded on an IPG strip $(24 \mathrm{~cm}$, $\mathrm{pH} 4-7$, linear) for isoelectric focusing (IEF) on an IPGphor isoelectric focusing system (GE Healthcare). The parameters were $30 \mathrm{~V}$ for $6 \mathrm{~h}$ (rehydration) at $20^{\circ} \mathrm{C}, 500 \mathrm{~V}$ for $1 \mathrm{~h}$, gradient $1,000 \mathrm{~V}$ for $1 \mathrm{~h}$, gradient $8,000 \mathrm{~V}$ for $2 \mathrm{~h}$ and $8,000 \mathrm{~V}$ for $7 \mathrm{~h}$. Following IEF, the strips were first equilibrated in equilibration solution of $50 \mathrm{mM}$ Tris- $\mathrm{HCl}$ (pH 8.8), $6 \mathrm{M}$ urea, 30\% (v/v) glycerol, $2 \%(\mathrm{w} / \mathrm{v})$ sodium dodecyl sulfate (SDS) and 1\% (w/v) DTT for $15 \mathrm{~min}$ and then again in the same solution without DTT [DTT was replaced with $4 \%(\mathrm{w} / \mathrm{v})$ iodoacetamide] for a further $15 \mathrm{~min}$. The IPG strips were then loaded onto $12.5 \%$ polyacrylamide gels in an Ettan DALTsix system (GE Healthcare) for electrophoresis at $1.5 \mathrm{~W} / \mathrm{gel}$ overnight until the bromophenol blue tracking dye reached the bottom of the gels.

Image acquisition and analysis. Fluorescent images were acquired using a Typhoon 9400 scanner (GE Healthcare) at a resolution of $100 \mu \mathrm{m}$. Matching, quantification and statistical analysis were carried out using DeCyder 2-D Differential Analysis software (GE Healthcare) and images were scanned manually to eliminate artifacts. Protein spots with at least a 1.3-fold increase or decrease in intensity between the control and $\mathrm{H}_{2} \mathrm{O}_{2}$-treated groups $(\mathrm{P}<0.05$, Student's t-test $)$ were considered as significantly differentially expressed proteins. Two other preparative gels with the control and $\mathrm{H}_{2} \mathrm{O}_{2}$-treated groups were made with $600 \mu \mathrm{g}$ of protein under the same conditions. The gels were fixed in $20 \%$ trichloroacetic acid (TCA) overnight and stained with PhastGel Blue. For further identification, the spots of interest were excised from the preparative gels using an Ettan Spot Picker (GE Healthcare).

Tryptic in-gel digestion of two-dimensional gel electrophoresis (2DE)-resolved proteins. Protein spots, which were excised from the preparative gels, were destained in $100 \mathrm{mM} \mathrm{NH} \mathrm{HCO}_{3} / 30 \%$ acetonitrile $(\mathrm{ACN})$. After removing the destaining buffer, the gel pieces were lyophilized and rehydrated in $30 \mu \mathrm{l}$ of $50 \mathrm{mM} \mathrm{NH} \mathrm{HCO}_{3}$ containing $50 \mathrm{ng}$ of trypsin (sequencing grade; Promega, Madison, WI, USA). Following overnight digestion at $37^{\circ} \mathrm{C}$, the peptides were extracted 3 times with $0.1 \%$ trifluoroacetic acid (TFA) in $60 \%$ ACN. The extracts were pooled together and lyophilized. The resulting lyophilized tryptic peptides were kept at $-80^{\circ} \mathrm{C}$ until 
mass spectrometric analysis was performed. A protein-free gel piece was treated as described above and used as the control to identify autoproteolysis products derived from trypsin.

MALDI-TOF/TOF MS and protein identification. MS and MS/MS spectra were obtained using the ABI 4800 Proteomics Analyzer (MALDI-TOF/TOF; Applied Biosystems, Foster City, CA, USA) operating in a result-dependent acquisition mode. Peptide mass maps were acquired in the positive ion reflector mode (20 kV accelerating voltage) with 1,000 laser shots/spectrum. Monoisotopic peak masses were automatically determined within the mass range of 800-4,000 Da with a signal-to-noise ratio minimum set to 10 and a local noise window width of $\mathrm{m} / \mathrm{z} 250$. Up to 10 of the most intense ions, with a minimum signal-to-noise ratio $>50$, were selected as precursors for MS/MS acquisition, excluding common trypsin autolysis peaks and matrix ion signals. In the MS/MS-positive ion mode, spectra were averaged with $2 \mathrm{kV}$ collision energy, and default calibration was set. Monoisotopic peak masses were automatically determined with a signal-to-noise ratio minimum set to 5 and a local noise window width of $\mathrm{m} / \mathrm{z} 250$. The MS together with MS/MS spectra were searched against the UniProtKB/Swiss-Prot database (Swiss-Prot 56.9) using GPS Explorer software (version 3.6; Applied Biosystems) and Mascot software (version 2.1; Matrix Science Inc., Boston, MA, USA) using the following parameter settings: trypsin cleavage, 1 missed cleavage allowed, carbamidomethylation set as fixed modification, oxidation of methionines allowed as variable modification, peptide mass tolerance set to $100 \mathrm{ppm}$, fragment tolerance set to $\pm 0.3 \mathrm{Da}$ and minimum ion score confidence interval for MS/MS data set to $95 \%$.

Western blot analysis. From the $\mathrm{H}_{2} \mathrm{O}_{2}$-treated group, $150 \mu \mathrm{g}$ of protein were minimally labelled with $\mathrm{Cy} 5$ fluorescent dye. Following incubation on ice for $30 \mathrm{~min}$, the reaction was terminated by the addition of $1 \mu \mathrm{l}$ of $10 \mathrm{mM}$ lysine. The proteins were then pooled and rehydration buffer ( $8 \mathrm{M}$ urea, $2 \%$ CHAPS, $0.4 \%$ IPG buffer and $0.28 \%$ DTT) was added to gain $250 \mu \mathrm{l}$ of final volume. The sample was loaded onto an IPG strip (13 cm, pH 4-7, linear) for IEF on an IPGphor isoelectric focusing system (GE Healthcare). The parameters were $30 \mathrm{~V}$ for $6 \mathrm{~h}$ (rehydration) at $20^{\circ} \mathrm{C}, 500 \mathrm{~V}$ for $1 \mathrm{~h}$, gradient $1,000 \mathrm{~V}$ for $1 \mathrm{~h}, \operatorname{grad} 8,000 \mathrm{~V}$ for $1 \mathrm{~h}$ and $8,000 \mathrm{~V}$ for $5 \mathrm{~h}$. Following IEF, the strips were first equilibrated in equilibration solution containing $50 \mathrm{mM}$ Tris- $\mathrm{HCl}$ (pH 8.8), $6 \mathrm{M}$ urea, 30\% (v/v) glycerol, $2 \%(\mathrm{w} / \mathrm{v}) \mathrm{SDS}$ and $1 \%(\mathrm{w} / \mathrm{v})$ DTT for $15 \mathrm{~min}$ and then again in the same solution without DTT [DTT was replaced with $4 \%$ $(\mathrm{w} / \mathrm{v})$ iodoacetamide] for a further $15 \mathrm{~min}$. The IPG strips were loaded onto $10 \%$ polyacrylamide gels for electrophoresis at $10 \mathrm{~mA}$ for $1 \mathrm{~h}$ followed by $30 \mathrm{~mA}$ until the bromophenol blue tracking dye reached the bottom of the gels. Fluorescent images were acquired using a Typhoon 9400 scanner (GE Healthcare) at a resolution of $100 \mu \mathrm{m}$. A $6 \times 6 \mathrm{~cm}$ gel containing protein was excised from the whole gel. Proteins were electrophoretically transferred onto a PVDF membrane (GE Healthcare). The membrane was blocked in TBS containing $0.1 \%$ Tween-20 (TBS-T) and 5\% fat-free milk for $1 \mathrm{~h}$. After a brief wash with TBS-T buffer, the membrane was incubated overnight at $4^{\circ} \mathrm{C}$ with mouse anti-human peroxiredoxin-3/thioredoxindependent peroxide reductase, mitochondrial (Prx-3) antibody

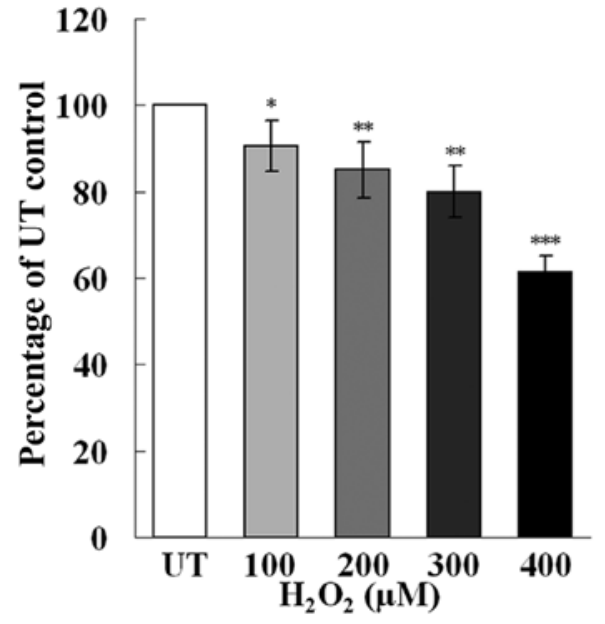

Figure 1. Proliferative ability of endothelial progenitor cells (EPCs) following exposure to $\mathrm{H}_{2} \mathrm{O}_{2}$-induced oxidative stress ssessed by MTT assay. Percentage of EPCs $3 \mathrm{~h}$ following treatment with $\mathrm{H}_{2} \mathrm{O}_{2}$. Results represent the means \pm SEM $\left(n=5 ;{ }^{*} \mathrm{P}<0.03,{ }^{* *} \mathrm{P}<0.01\right.$ and ${ }^{* * *} \mathrm{P}<0.0001$ by Student's paired t-test). UT, untreated.

(Abcam, Cambridge, UK) diluted in TBS-T buffer (1:1,000 dilution). The primary antibody was removed, and the membrane was washed extensively in TBS-T buffer. Subsequent incubation with goat anti-mouse antibody (1:500) pre-adsorbed with Cy3 (Abcam) was performed at room temperature for $2 \mathrm{~h}$. The membrane was washed extensively in TBS-T buffer to remove the secondary antibody. Fluorescent images were acquried using a Typhoon 9400 scanner (GE Healthcare) at a resolution of $100 \mu \mathrm{m}$.

Statistical analysis. Data are expressed as the means \pm SEM. Differences between groups were analyzed using Student's t-tests. A value of $\mathrm{P}<0.05$ was considered to indicate a statistical significant difference.

\section{Results}

Tube-forming ability of EPCs is affected to a greater extent following exposure to oxidative stress. To investigate the effects of oxidative stress on EPCs, the cells were pre-treated with $\mathrm{H}_{2} \mathrm{O}_{2}$ at different final concentrations (100-400 $\left.\mu \mathrm{M}\right)$ for $3 \mathrm{~h}$ prior to the following experiments. MTT, scratch-wound and Matrigel invasion assay were performed to examine the proliferation, migration and tube-forming ability of the EPCs, respectively. The results were similar to those from our previous study (17). Treatment with $\mathrm{H}_{2} \mathrm{O}_{2}$ resulted in a dose-dependent decrease in cell proliferation (Fig. 1) and cell migration (Fig. 2). Additionally, treatment with $\mathrm{H}_{2} \mathrm{O}_{2}$ at a final concentration of $300 \mu \mathrm{M}$ markedly impaired cell migration compared with the control group ( $33 \%$ decrease). At a final $\mathrm{H}_{2} \mathrm{O}_{2}$ concentration of $400 \mu \mathrm{M}$, cell migration was completely suppressed. These data suggest that following exposure to oxidative stress, the migration ability and survival of EPCs is impaired.

To examine the capillary tube-forming ability of EPCs following exposure to oxidave stress, we performed Matrigel invasion assay and the tube-forming ability of the EPCs was observed over a period of $24 \mathrm{~h}$. After $8 \mathrm{~h}$, we observed the initiation of capillary-like structures in the untreated and 


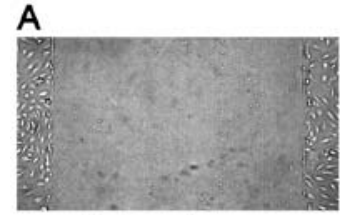

Wound area

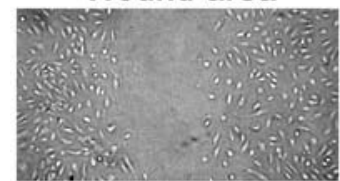

$100 \mu \mathrm{M}$

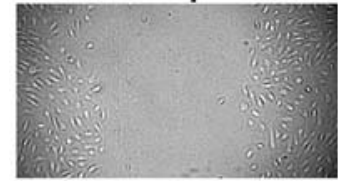

$300 \mu \mathrm{M}$

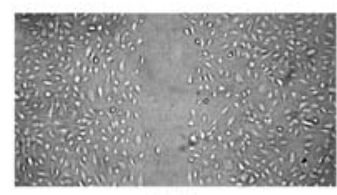

UT

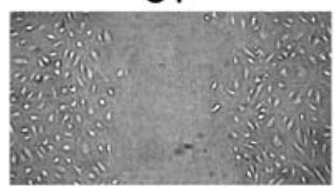

$200 \mu \mathrm{M}$

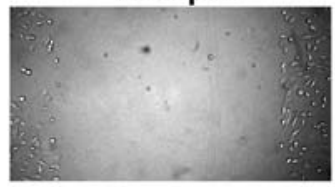

$400 \mu \mathrm{M}$
B

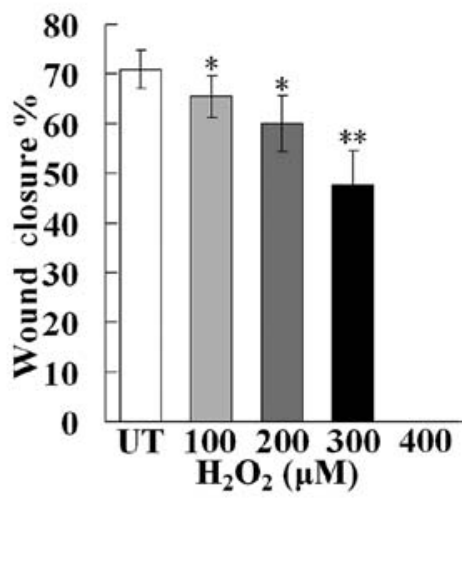

Figure 2. Migration ability of endothelial progenitor cells (EPCs) following exposure to $\mathrm{H}_{2} \mathrm{O}_{2}$-induced oxidative stress. EPCs untreated or treated with increasing concentrations of $\mathrm{H}_{2} \mathrm{O}_{2}$ for $3 \mathrm{~h}$ were scraped using a sterile micropipette tip and then incubated for $18 \mathrm{~h}$. (A) Representative photomicrographs (magnification, x100) of EPCs migrating to the wounded area at 0 or $18 \mathrm{~h}$ after scraping. Data shown are representative of 5 independent experiments. (B) Quantification of EPC migration ratio. There was no migration detected at $400 \mu \mathrm{M}$. Results represent the means \pm SEM ( $\mathrm{n}=5$; ${ }^{*} \mathrm{P}<0.01$ and ${ }^{* * *} \mathrm{P}<0.003$ by Student's paired t-test). UT, untreated.

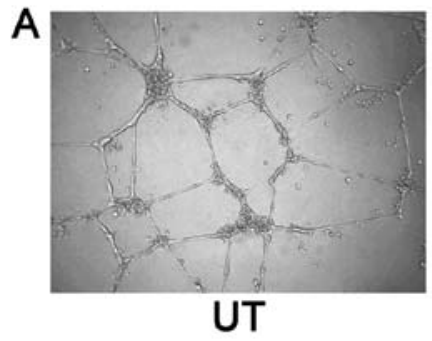

B

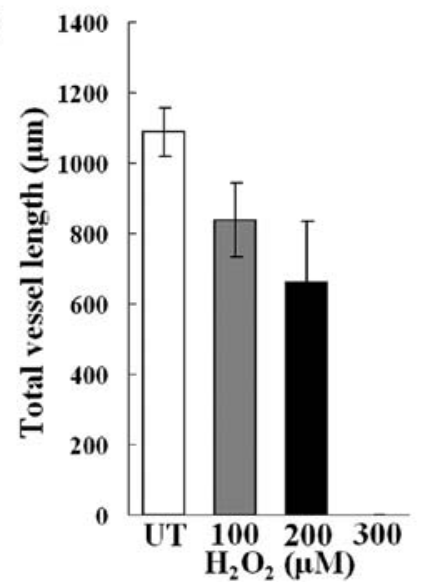

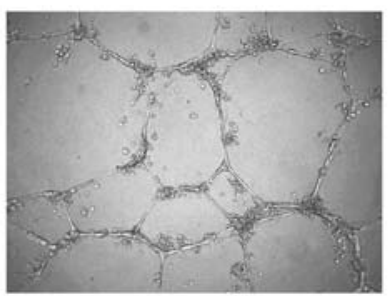

$100 \mu \mathrm{M}$

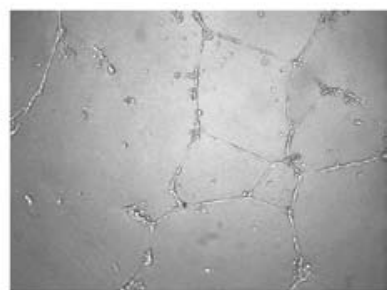

$200 \mu \mathrm{M}$

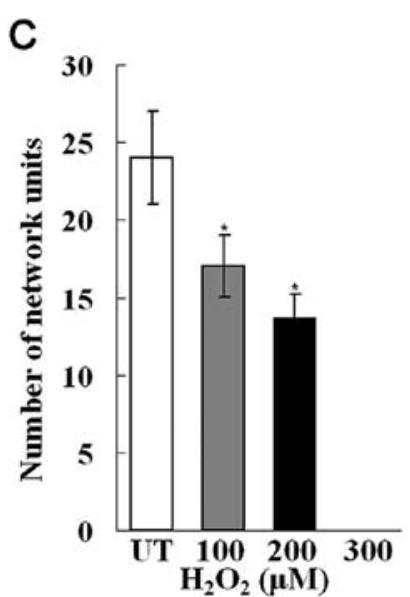

Figure 3. Tube-forming ability of endothelial progenitor cells (EPCs) following exposure to $\mathrm{H}_{2} \mathrm{O}_{2}$-induced oxidative stress. EPCs untreated or treated with increasing concentrations of $\mathrm{H}_{2} \mathrm{O}_{2}$ for $3 \mathrm{~h}$ were seeded in the Matrigel and then incubated for $24 \mathrm{~h}$. (A) Representative photomicrographs (magnification, $\mathrm{x} 100$ ) of EPCs. Data shown are representative of 3 independent experiments. (B) Quantification of capillary vessel length. Data represent the average total capillary vessel length/image obtained \pm SEM ( $n=3, \mathrm{P}<0.05$ by Student's paired t-test). There was no vessel formation detected at $300 \mu$ M. (C) Quantification of vessel density. Data represent the average number of closed network units/central visual field of each well \pm SEM $\left(n=3 ;{ }^{*} \mathrm{P}<0.02\right.$ by Student's paired $\mathrm{t}$-test).

$\mathrm{H}_{2} \mathrm{O}_{2}$-treated EPCs. However, after $24 \mathrm{~h}$, the EPCs treated with $\mathrm{H}_{2} \mathrm{O}_{2}$ exhibited reduced vessel length and closed network units (Fig. 3), suggesting that the EPCs failed to form effective tubules due to oxidative stress. In addition, following treatment with $\mathrm{H}_{2} \mathrm{O}_{2}$ at a final concentration of $300 \mu \mathrm{M}$, there was no part or closed network unit formation, although cells still proliferated and migrated at this concentration. This suggests that the tube-forming ability of the EPCs is affected to greater extent in response to oxidative stress.

$2 \mathrm{DE}$ of $\mathrm{H}_{2} \mathrm{O}_{2}$-treated EPCs and identification of differentially expressed proteins. To identify the proteins involved in the 
Table I. Summary of differentially expressed proteins in EPCs in response to exposure to $\mathrm{H}_{2} \mathrm{O}_{2}$-induced oxidative stress.

\begin{tabular}{llcccc}
\hline $\begin{array}{l}\text { Spot } \\
\text { no. }\end{array}$ & \multicolumn{1}{c}{ Protein identity } & $\begin{array}{c}\text { Swiss-Prot } \\
\text { no. }\end{array}$ & $\begin{array}{c}\text { Relative spot } \\
\text { altered ratio \% } \\
\left(\mathrm{H}_{2} \mathrm{O}_{2} / \text { control, 100\% }\right)\end{array}$ & pI/Mr & $\begin{array}{c}\text { Mascot } \\
\text { score }\end{array}$ \\
\hline 1 & EGF-containing fibulin-like extracellular matrix protein 1 & $\mathrm{Q} 12805$ & 146 & $4.95 / 56.9$ & 440 \\
2 & Rab GDP dissociation inhibitor $\alpha$ & $\mathrm{P} 31150$ & 137 & $5 / 51.2$ & 137 \\
3 & Vimentin & $\mathrm{P} 08670$ & 151 & $5.06 / 53.7$ & 351 \\
4 & ADP-sugar pyrophosphatase & $\mathrm{Q} 9 \mathrm{UKK} 9$ & 69 & $4.87 / 24.6$ & 200 \\
5 & Peroxiredoxin-2 & $\mathrm{P} 32119$ & 273 & $5.66 / 22.0$ & 335 \\
6 & Thioredoxin-dependent peroxide reductase, mitochondrial & $\mathrm{P} 30048$ & 286 & $7.67 / 28.0$ & 277 \\
7 & Peroxiredoxin-6 & $\mathrm{P} 30041$ & 307 & $6 / 25.1$ & 725 \\
8 & Triosephosphate isomerase & $\mathrm{P} 60174$ & 70 & $6.45 / 26.94$ & 299 \\
\hline
\end{tabular}

EPCs, endothelial progenitor cells; pI, isoelectric point; Mr, molecular mass.

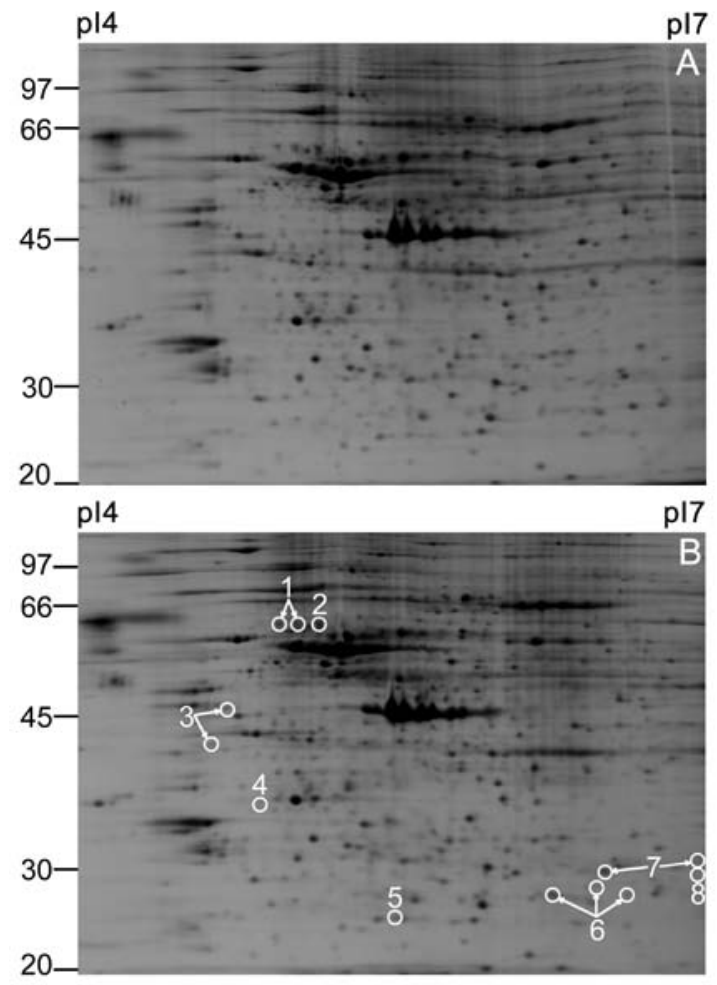

Figure 4. Coomassie brilliant blue-stained 2D gel electrophoresis of proteins extracted from the (A) untreated and (B) $200 \mu \mathrm{M} \mathrm{H}_{2} \mathrm{O}_{2}$-treated endothelial progenitor cells (EPCs). Total protein $(600 \mu \mathrm{g})$ from 4 passages of EPCs was subjected in $24 \mathrm{~cm}$ linear IPG strips, with a $\mathrm{pH}$ range of 4-7, followed by $12.5 \%$ SDS-polyacrylamide gel electrophoresis. The molecular mass of the markers is indicated along the gels. The detailed information of identified proteins is listed in Table I.

protection of EPCs under oxidative stress conditions, comparative proteomic analysis was performed. Representative $2 \mathrm{DE}$ gel images from the untreated control group and $\mathrm{H}_{2} \mathrm{O}_{2}$-treated group are shown in Fig. 4. A total of 11 upregulated protein spots and 2 downregulated protein spots were observed in the $\mathrm{H}_{2} \mathrm{O}_{2}$-treated group compared with control group, which are indicated by circles (Fig. 4B). The pixel volume of each spot was calculated, normalized and compared between the 2 groups using the Student's t-test. For all the selected spots, the P-values between the untreated control and $\mathrm{H}_{2} \mathrm{O}_{2}$-treated groups were $<0.05$.

The differentially expressed protein spots were excised from the preparative gels, subjected to trypsin digestion, and identified using MALDI-TOF/TOF MS. The peptide mass peaks and peptide sequences were compared with those in the Swiss-Prot database. Eight proteins were identified successfully, 6 of which were upregulated and the remainder were downregulated. Table I shows the Swiss-Prot accession number, theoretical molecular weight and the isoelectric point (pI) of each protein spot, altered ratio $\left(\mathrm{H}_{2} \mathrm{O}_{2}\right.$-treated/control group) and the protein scores of each protein. In some cases, 1 protein was identified in several discrete spots, presumably representing protein modifications (such as spot 6), suggesting post-translational modifications consisting of the addition or removal of a small charged moiety. However, the specific nature of these modifications cannot be ascertained from the present data.

Proteins with altered expression patterns following exposure to $\mathrm{H}_{2} \mathrm{O}_{2}$-induced oxidative stress, were categorized into several groups according to their putative/known functions. The major group contained anti-oxidative proteins, including peroxiredoxin-2 (Prx-2), Prx-3 and peroxiredoxin-6 (Prx-6), all of which were upregulated. Vimentin and EGF-containing fibulin-like extracellular matrix protein 1 (EFEMP1), cytoskeleton proteins, were upregulated. In addition, ADP-sugar pyrophosphatase (NUDT5) and triose-phosphate isomerase (TIM) were downregulated.

Western blot analysis. In order to demonstrate that protein 6 (Fig. 4B) was Prx-3, western blot analysis was performed. Firstly, whole cell proteins were separated by $2 \mathrm{DE}$ and a fluorescent image was acquired (Fig. 5A). A $6 \times 6 \mathrm{~cm}$ square area, indicated in Fig. 5A, was excised. Proteins were electrophoretically transferred onto a PVDF membrane and scanned using Cy5 (Fig. 5B) and Cy3 (Fig. 5C). Protein 6 was detected both by Cy5 (Fig. 5B) and Cy3 (Fig. 5C), suggesting that protein 6 was actually Prx-3. 

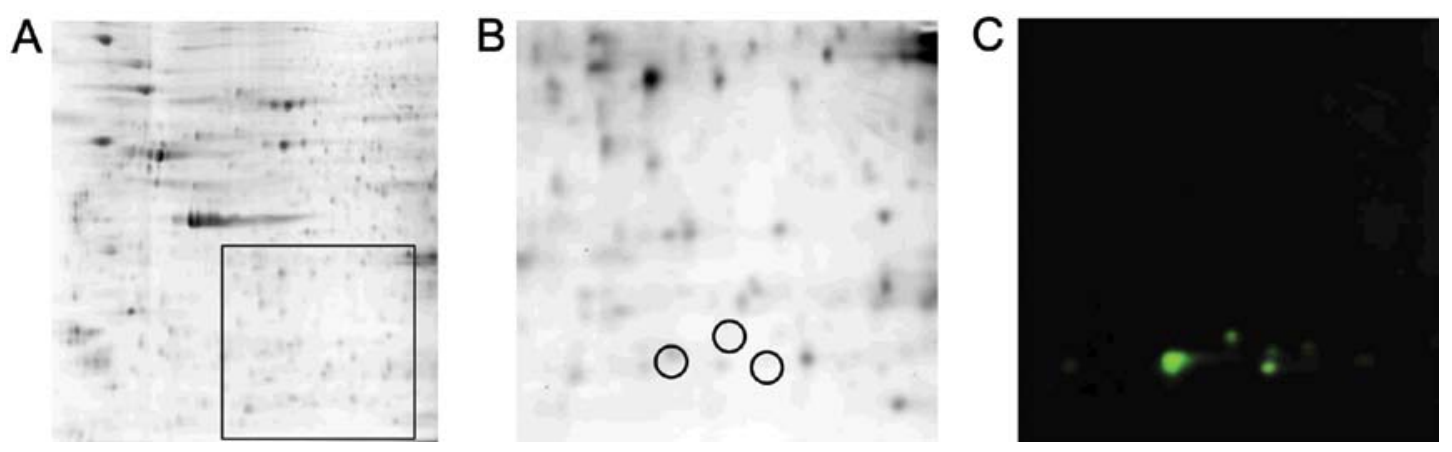

Figure 5. Western blot analysis of thioredoxin-dependent peroxide reductase (Prx-3) expression following treatment with $200 \mu \mathrm{M} \mathrm{H}_{2} \mathrm{O}_{2}$ for $3 \mathrm{~h}$. Cy5-labelled cell proteins $(15 \mu \mathrm{g})$ were subjected to $13 \mathrm{~cm} \mathrm{pH} 4-7$ isoelectric focusing (IEF) electrophoresis followed by $10 \%$ SDS-PAGE isolation. Fluorescent images were acquired using a Typhoon 9400 scanner. (A) Fluorescent image (scanned image) of proteins labelled with Cy5 on the 2DE gel. The square is the area used for western blot analysis. (B) Fluorescent image (scanned image) of proteins labelled with Cy5 on the PVDF membrane. Prx-3 is indicated with circles. (C) Fluorescent image of Prx-3 scanned with Cy3 on the PVDF membrane.

\section{Discussion}

EPCs, which circulate in peripheral blood vessels, can be recruited to damaged vessels or tissues and participate in vascular repair and neovascularization. Thus, the enhancement of EPC number and function is a novel therapeutic approach to vascular diseases. Studies have shown that vascular diseases, including hypertension, diabetes and atherosclerosis, are characterized by elevated levels of ROS (14). To comprehensively determine alterations in protein expression in response to oxidative stress in EPCs, we performed a proteomic analysis using 2D-DIGE followed by MALDI-TOF/TOF MS. We identified 8 proteins which were differentially expressed in the untreated and $\mathrm{H}_{2} \mathrm{O}_{2}$-treated cells, and 6 were upregulated and 2 were downregulated. Finally, a spot from the 2D-DIGE gel (protein 6) was selected to further confirm the results from MS by western blot analysis.

It has been reported that several antioxidant enzymes, including catalase, MnSOD and GPx-1 are highly expressed in EPCs in response to oxidative stress (14-16). In the present study, 3 antioxidant enzymes, Prx-2, Prx-3 and Prx-6, were found to be upregulated in response to $\mathrm{H}_{2} \mathrm{O}_{2}$-induced oxidative stress. All 3 enzymes belong to the peroxiredoxin (Prx) family, which is involved in redox regulation of cell survival. They commonly exhibit peroxidase activity, which is dependent on reduced forms of thioredoxin and/or glutathione (18). Prx-2 reduces peroxides by reducing equivalents through the thioredoxin system, plays an important role in eliminating peroxides generated during metabolism, and participates in the signaling cascades of growth factors and tumor necrosis factor- $\alpha$ by regulating the intracellular concentrations of $\mathrm{H}_{2} \mathrm{O}_{2}$ (19). Prx-3 protects radical-sensitive enzymes from oxidative damage. Its gene expression is induced by oxidative stress and appears to function as an antioxidant in the cardiovascular system (18). Bovine aortic endothelial cells with an elevated level of Prx-3 due to exposure to mild oxidative stress have been shown to be more tolerant to subsequent exposure to severe oxidative stress (19). Prx-6 plays a role in the regulation of phospholipid turnover, as well as in the protection against oxidative injury (18). Taken together, these data suggest that the upregulation of antioxidant enzymes from the Prx family protects EPCs from oxidative injury.
Apart from antioxidant enzymes, alterations in protein expression induced by mild oxidative stress are also observed in cytoskeleton proteins. EFEMP1 (fibulin-3), which belongs to the fibulin family, is an extracellular glycoprotein and is mainly localized in the walls of capillaries and basement membrane of the large but not distal airways $(20,21)$. Studies have demonstrated that EFEMP1 promotes neovascularization by increasing the expression level of vascular endothelial growth factor (VEGF) $(22,23)$. Accordingly, the upregulation of EFEMP1 may partially explain our discovery that there was no difference in tube formation between the untreated EPCs and those treated with 100 or $200 \mu \mathrm{M} \mathrm{H}_{2} \mathrm{O}_{2}$ at $8 \mathrm{~h}$ after seeding on Matrigel.

Another upregulated cytoskeleton protein in our study was vimentin. It belongs to the intermediate filaments (IFs) family and is the only cytoplasmic IF found in macrophages, lymphocytes, neutrophils, endothelial cells and fibroblasts $(24,25)$. It has been demonstrated that the mitochondria are less sensitive to ROS in cells containing vimentin than in cells devoid of vimentin, suggesting that vimentin protects the mitochondria from oxidative stress (25). Therefore, the upregulation of vimentin in the $\mathrm{H}_{2} \mathrm{O}_{2}$-treated EPCs may be a compensatory mechanism in order to protect the cells from oxidative damage. Consistent with our finding, an in vitro study using HepG2 cells revealed that pre-treatment with low concentrations of $\mathrm{H}_{2} \mathrm{O}_{2}(50 \mu \mathrm{M})$ induced increased levels of vimentin, and reduced the cleavage of vimentin following exposure to oxidative stress (26). It has been reported that the cleavage of vimentin by caspases results in the disruption of its filamentous structure, which may promote apoptosis by facilitating nuclear condensation and subsequent fragmentation and amplifying the cell death signal (26). Thus, fewer EPCs may undergo apoptosis induced by oxidative stress through the upregulation of vimentin. This may be a compensatory mechanism through which the EPCs protect themselves from damage due to oxidative stress. In addition, vimentin has been shown to be associated with the organization of proteins that are involved in adhesion, migration and cell signaling, and the loss of vimentin leads to a lack of integrity in the vascular endothelium (27). In support of a role for vimentin in the transmigration of myeloid cells, vimentin has been reported to reside in the filopodia and podosomes of adherent macrophages (27). Podosomes 
are early cell adhesion structures found in myeloid cells that are crucial for directional movement and transmigration (27). Therefore, the upregulation of vimentin may partially enhance the migration ability and survival ECPs following exposure to oxidative stress.

Though multiple defensive responses exist, our data revealed that treatment with $\mathrm{H}_{2} \mathrm{O}_{2}$ induced a concentrationdependent reduction in EPC number and function. In addition, the tube-forming ability and function were found to be affected to a greater extent following exposure to oxidative stress, suggesting that EPCs have an impaired function in neovascularization under oxidative stress conditions. These results may explain the clinical findings that the number of EPCs inversely correlates with the risk of cardiovascular and cerebrovascular events $(2,5,28-32)$. Thus, there may be proteins or pathways through which $\mathrm{H}_{2} \mathrm{O}_{2}$ exerts its negative effects on EPCs. In this study, we found 3 proteins that may be involved in the loss of EPC number and function following treatment with $\mathrm{H}_{2} \mathrm{O}_{2}$. Rab GDP dissociation inhibitor $\alpha$ (Rab GDI $\alpha$ ) was upregulated, and NUDT5 and TIM were downregulated.

Rab proteins are small GTP-binding proteins that are important in the vesicular trafficking of molecules between cellular organelles (33). They act as molecular switches, cycling between 'inactive' GDP-bound and 'active' GTP-bound states (34). Rab GDI $\alpha$ is an important factor in the control of $\mathrm{Rab}$ and the specificity of vesicular transport. By binding Rab, released after membrane fusion, Rab GDI $\alpha$ prevents Rab from releasing its GDP molecule until it has interacted with appropriate proteins in the donor membrane $(33,35,36)$. Therefore, an upregulation of Rab GDI $\alpha$ may lead to the reduction of signal transduction among cellular organelles and the survival of EPCs following oxidative damage.

Human NUDT5, which has an intrinsic activity to cleave ADP sugars to AMP and sugar phosphate, possesses the ability to degrade 8-oxo-dGDP to monophosphate. Since 8-oxo-dGDP and 8-oxo-dGTP are inter-convertible by cellular enzymes, NUDT5 has the potential to prevent errors during DNA replication. As a 'sanitization enzyme', NUDT5 has the potential to eliminate endogenous toxic materials from the cell and the mutagenic oxidized substrates from the nucleotide pool in order to prevent their toxic effects $(37,38)$. In our study, the downregulation of NUDT5 suggests a high error rate in DNA replication due to oxidative stress, resulting in EPC apoptosis.

TIM is considered an important biocatalyst during glycolysis and rapidly interconverts dihydroxyacetone phosphate and D-glyceraldehyde-3-phosphate (39). It has been demonstrated that the energy metabolism of endothelial cells is characterized by glucose fermentation to lactate even under normoxic conditions ('aerobic glycolysis'). This is possibly an adaptation to the oxidative environment since 'aerobic glycolysis' can help reduce the production of oxygen radicals. 'Aerobic glycolysis' is also linked to cell proliferation. A correlation has been established between the amount of lactate produced and the cell doubling time (40). The downregulation of TIM induces a reduction in energy production and reduces EPC proliferation, which is consistent with the results from our study. We hypothesized that even if vimentin and EFEMP1 expression is upregulated in the EPCs, enhancing the migration and tube-forming ability and survival of EPCs, the lack of energy may still lead to the impaired function of EPCs under oxidative stress conditions.
In conclusion, our results demonstrated that $\mathrm{H}_{2} \mathrm{O}_{2}$-induced oxidative stress modified the levels of 8 proteins that are associated with defensive responses against oxidative stress, energy production, signal transduction and the elimination of oxidative nucleotides. Despite the defensive responses, including the upregulation of antioxidant enzymes ( $>2.5$-fold) and cytoskeleton proteins, EPCs still dysfunction due to the altered expression of proteins associated with energy production, signal transduction and the elimination of oxidative nucleotides. The data presented in this study indicate that in order to increase the function and number of EPCs, we should focus on defensive proteins, as well as protective proteins, such as Rab GDI $\alpha$, NUDT5 and TIM.

\section{References}

1. Shantsila E, Watson T and Lip GY: Endothelial progenitor cells in cardiovascular disorders. J Am Coll Cardiol 49: 741-752, 2007.

2. Rouhl RP, van Oostenbrugge RJ, Damoiseaux J, Tervaert JW and Lodder J: Endothelial progenitor cell research in stroke: a potential shift in pathophysiological and therapeutical concepts. Stroke 39: 2158-2165, 2008.

3. Sen S, McDonald SP, Coates PT and Bonder CS: Endothelial progenitor cells: novel biomarker and promising cell therapy for cardiovascular disease. Clin Sci (Lond) 120: 263-283, 2011.

4. Zampetaki A, Kirton JP and Xu Q: Vascular repair by endothelial progenitor cells. Cardiovasc Res 78: 413-421, 2008.

5. Lapergue B, Mohammad A and Shuaib A: Endothelial progenitor cells and cerebrovascular diseases. Prog Neurobiol 83: 349-362, 2007.

6. Ward MR, Stewart DJ and Kutryk MJ: Endothelial progenitor cell therapy for the treatment of coronary disease, acute MI, and pulmonary arterial hypertension: current perspectives. Catheter Cardiovasc Interv 70: 983-998, 2007.

7. Dobert N, Britten M, Assmus B, Berner U, Menzel C, Lehmann R, Hamscho N, Schachinger V, Dimmeler S, Zeiher AM and Grunwald F: Transplantation of progenitor cells after reperfused acute myocardial infarction: evaluation of perfusion and myocardial viability with FDG-PET and thallium SPECT. Eur J Nucl Med Mol Imaging 31: 1146-1151, 2004.

8. Flores-Ramirez R, Uribe-Longoria A, Rangel-Fuentes MM, Gutierrez-Fajardo P, Salazar-Riojas R, Cervantes-Garcia D, Trevino-Ortiz JH, Benavides-Chereti GJ, Espinosa-Oliveros LP, Limon-Rodriguez $\mathrm{RH}$, et al: Intracoronary infusion of $\mathrm{CD}^{2} 3^{+}$ endothelial progenitor cells improves heart function and quality of life in patients with chronic post-infarct heart insufficiency. Cardiovasc Revasc Med 11: 72-78, 2010.

9. Haendeler J, Hoffmann J, Diehl JF, Vasa M, Spyridopoulos I, Zeiher AM and Dimmeler S: Antioxidants inhibit nuclear export of telomerase reverse transcriptase and delay replicative senescence of endothelial cells. Circ Res 94: 768-775, 2004.

10. Ogita $\mathrm{H}$ and Liao J: Endothelial function and oxidative stress. Endothelium 11: 123-132, 2004.

11. Madamanchi NR, Vendrov A and Runge MS: Oxidative stress and vascular disease. Arterioscler Thromb Vasc Biol 25: 29-38, 2005.

12. Alexandrova ML and Bochev PG: Oxidative stress during the chronic phase after stroke. Free Radic Biol Med 39: 297-316, 2005.

13. Case J, Ingram DA and Haneline LS: Oxidative stress impairs endothelial progenitor cell function. Antioxid Redox Signal 10: 1895-1907, 2008.

14. Dernbach E, Urbich C, Brandes RP, Hofmann WK, Zeiher AM and Dimmeler S: Antioxidative stress-associated genes in circulating progenitor cells: evidence for enhanced resistance against oxidative stress. Blood 104: 3591-3597, 2004.

15. Imanishi T, Tsujioka $H$ and Akasaka T: Endothelial progenitor cells dysfunction and senescence: contribution to oxidative stress. Curr Cardiol Rev 4: 275-286, 2008.

16. He T, Peterson TE, Holmuhamedov EL, Terzic A, Caplice NM, Oberley LW and Katusic ZS: Human endothelial progenitor cells tolerate oxidative stress due to intrinsically high expression of manganese superoxide dismutase. Arterioscler Thromb Vasc Biol 24: 2021-2027, 2004. 
17. Wei J, Liu Y, Chang M, Sun CL, Li DW, Liu ZQ and Hu LS: Proteomic analysis of oxidative modification in endothelial colony-forming cells treated by hydrogen peroxide. Int J Mol Med 29: 1099-1105, 2012.

18. Fujii $\mathrm{J}$ and Ikeda Y: Advances in our understanding of peroxiredoxin, a multifunctional, mammalian redox protein. Redox Rep 7: 123-130, 2002.

19. Rhee SG, Kang SW, Chang TS, Jeong W and Kim K: Peroxiredoxin, a novel family of peroxidases. IUBMB Life 52: 35-41, 2001.

20. Kobayashi N, Kostka G, Garbe JH, Keene DR, Bachinger HP, Hanisch FG, Markova D, Tsuda T, Timpl R, Chu ML and Sasaki T: A comparative analysis of the fibulin protein family. Biochemical characterization, binding interactions, and tissue localization. J Biol Chem 282: 11805-11816, 2007.

21. Timpl R, Sasaki T, Kostka G and Chu ML: Fibulins: a versatile family of extracellular matrix proteins. Nat Rev Mol Cell Biol 4: 479-489, 2003.

22. Song EL, Hou YP, Yu SP, Chen SG, Huang JT, Luo T, Kong LP, $\mathrm{Xu} \mathbf{J}$ and Wang HQ: EFEMP1 expression promotes angiogenesis and accelerates the growth of cervical cancer in vivo. Gynecol Oncol 121: 174-180, 2011.

23. Roybal CN, Marmorstein LY, Vander Jagt DL and Abcouwer SF Aberrant accumulation of fibulin-3 in the endoplasmic reticulum leads to activation of the unfolded protein response and VEGF expression. Invest Ophthalmol Vis Sci 46: 3973-3979, 2005.

24. Muller K, Dulku S, Hardwick SJ, Skepper JN and Mitchinson MJ: Changes in vimentin in human macrophages during apoptosis induced by oxidised low density lipoprotein. Atherosclerosis 156: $133-144,2001$.

25. Zamoner A, Barreto KP, Filho DW, Sell F, Woehl VM, Guma FC, Silva FR and Pessoa-Pureur R: Hyperthyroidism in the developing rat testis is associated with oxidative stress and hyperphosphorylated vimentin accumulation. Mol Cell Endocrinol 267: 116-126, 2007.

26. Chen X, Kang H and Zou F: Low concentration of GA activates a preconditioning response in HepG2 cells during oxidative stressroles of Hsp90 and vimentin. Cell Stress Chaperones 14: 381-389, 2009.

27. Ivaska J, Pallari HM, Nevo J and Eriksson JE: Novel functions of vimentin in cell adhesion, migration, and signaling. Exp Cell Res 313: 2050-2062, 2007.

28. Ghani U, Shuaib A, Salam A, Nasir A, Shuaib U, Jeerakathil T, Sher F, O'Rourke F, Nasser AM, Schwindt B and Todd K: Endothelial progenitor cells during cerebrovascular disease. Stroke 36: 151-153, 2005
29. Hill JM, Zalos G, Halcox JP, Schenke WH, Waclawiw MA, Quyyumi AA and Finkel T: Circulating endothelial progenitor cells, vascular function, and cardiovascular risk. N Engl J Med 348: 593-600, 2003.

30. Werner N, Wassmann S, Ahlers P, Schiegl T, Kosiol S, Link A, Walenta K and Nickenig G: Endothelial progenitor cells correlate with endothelial function in patients with coronary artery disease. Basic Res Cardiol 102: 565-571, 2007.

31. Schmidt-Lucke C, Rossig L, Fichtlscherer S, Vasa M, Britten M, Kamper U, Dimmeler S and Zeiher AM: Reduced number of circulating endothelial progenitor cells predicts future cardiovascular events: proof of concept for the clinical importance of endogenous vascular repair. Circulation 111: 2981-2987, 2005.

32. Briguori C, Testa U, Riccioni R, Colombo A, Petrucci E, Condorelli G, Mariani G, D'Andrea D, De Micco F, Rivera NV, et al: Correlations between progression of coronary artery disease and circulating endothelial progenitor cells. FASEB J 24: 1981-1988, 2010.

33. Wang P, Chintagari NR, Narayanaperumal J, Ayalew S, Hartson S and Liu L: Proteomic analysis of lamellar bodies isolated from rat lungs. BMC Cell Biol 9: 34, 2008.

34. Seabra MC and Wasmeier C: Controlling the location and activation of Rab GTPases. Curr Opin Cell Biol 16: 451-457, 2004.

35. Yamaguchi Y, Miyagi Y and Baba H: Two-dimensional electrophoresis with cationic detergents: a powerful tool for the proteomic analysis of myelin proteins. Part 2: analytical aspects. J Neurosci Res 86: 766-775, 2008.

36. Poirrier JE, Guillonneau F, Renaut J, Sergeant K, Luxen A, Maquet $\mathrm{P}$ and Leprince $\mathrm{P}$ : Proteomic changes in rat hippocampus and adrenals following short-term sleep deprivation. Proteome Sci 6: 14, 2008.

37. Ito R, Sekiguchi M, Setoyama D, Nakatsu Y, Yamagata Y and Hayakawa $\mathrm{H}$ : Cleavage of oxidized guanine nucleotide and ADP sugar by human NUDT5 protein. J Biochem 149: 731-738, 2011.

38. Kamiya $\mathrm{H}$, Hori M, Arimori T, Sekiguchi M, Yamagata $Y$ and Harashima H: NUDT5 hydrolyzes oxidized deoxyribonucleoside diphosphates with broad substrate specificity. DNA Repair (Amst) 8: 1250-1254, 2009.

39. Wierenga RK,Kapetaniou EG and Venkatesan R: Triosephosphate isomerase: a highly evolved biocatalyst. Cell Mol Life Sci 67 3961-3982, 2010

40. Peters K, Kamp G, Berz A, Unger RE, Barth S, Salamon A, Rychly J and Kirkpatrick CJ: Changes in human endothelial cell energy metabolic capacities during in vitro cultivation. The role of 'aerobic glycolysis' and proliferation. Cell Physiol Biochem 24: 483-492, 2009. 